\title{
Photodynamic Toxicity of Chlorophyllin against Fasciola gigantica Carrier Snail Indoplanorbis exustus in Visible Spectral Band
}

\author{
Divya Chaturvedi, Dinesh Kumar Singh and Vinay Kumar Singh*
}

\section{Divya Chaturvedi, Dinesh Kumar Singh and Vinay Kumar Singh*}

Malacology Laboratory, Department of Zoology, D.D.U. Gorakhpur University, Gorakhpur, Uttar Pradesh, Pin: 273 009, INDIA.

\section{Correspondence}

\section{Dr. Vinay Kumar Singh}

Malacology Laboratory, Department of Zoology, D.D.U. Gorakhpur University, Gorakhpur, Uttar Pradesh, Pin: 273 009, INDIA.

Phone no: (O) +91-551-2202187; (M) +91-9415855488

E-mail: vinaygkpuniv@gmail.com

\section{History}

- Submission Date: 02-05-2017;

- Review completed: 08-06-2017.

- Accepted Date: 22-08-2017.

\section{DOI : 10.5530/pj.2017.6.115}

Article Available online

http://www.phcogj.com/v9/i6

\section{Copyright}

(C) 2017 Phcog.Net. This is an openaccess article distributed under the terms of the Creative Commons Attribution 4.0 International license.

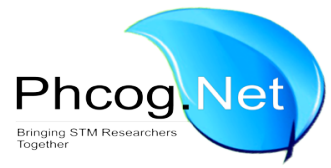

\begin{abstract}
Background: Fasciolosis is one of the most debilitating diseases caused by liver flukes Fasciola hepatica and F. gigantica. Snail Lymnaeidae and Planorbidae is the intermediate host of these flukes. Snail population management is a good tool to control fasciolosis because gastropods represent the weakest link in the life-cycle of trematode. Aim of the present study is to explore the molluscicidal activity of chlorophyllin in visible spectral band against Fasciola gigantica carrier snail Indoplanorbis exustus. Methods: Chlorophyll was transformed into water-soluble chlorophyllin in $100 \%$ ethanol by using different types of chemicals. Ten snails Indoplanorbis exustus were placed in a glass aquarium containing $3 \mathrm{~L}$ of dechlorinated tap water. These snails were treated with different concentrations of chlorophyllin in sunlight as well as exposed to different visible spectral band of light. Results: Pure chlorophyllin ( $96 \mathrm{~h}$ $\left.\mathrm{LC}_{50} 6.54 \mathrm{mg} / \mathrm{l}\right)$ in sunlight was more toxic than extracted chlorophyllin (96 h LC $939.65 \mathrm{mg} / \mathrm{l}$ ). There was a significant variation in the toxicity of chlorophyllin with snails, exposed to visible spectral band of light. The highest and lowest toxicity of chlorophyllin against I. exustus was noted in yellow light (96 h LC ${ }_{50} 2016.79 \mathrm{mg} / \mathrm{l}$ ) and green light $\left(96 \mathrm{~h} \mathrm{LC}_{50} 2433.16 \mathrm{mg} / \mathrm{l}\right)$. High performance liquid chromatography (HPLC) study reveals that the active molluscicidal component extracted in spinach leaves is chlorophyllin. Conclusion: Due to the photodynamic nature of chlorophyllin, it has the potential to control the population of vector snails and ultimately fasciolosis in developing countries.

Key words: Fasciolosis, Photodynamic Product, Chlorophyllin, Indoplanorbis exustus, Visible light band.
\end{abstract}

\section{INTRODUCTION}

Fasciolosis is water and food borne zoonotic disease caused by two trematode species Fasciola hepatica and F. gigantica. ${ }^{1,2}$ As being linked with fasciolosis it cause dramatic losses of economic prosperity of any country and classified as re-emerging human disease. ${ }^{3}$ It caused low fertility, reduced meat and milk yield in infected cattle population. ${ }^{3}$ In early eighties, Singh and Agarwal ${ }^{4}$ noted that $94 \%$ of buffaloes slaughtered at the abattoirs in Gorakhpur district of eastern Uttar Pradesh (India), are infected by Fasciola gigantica, which still persisted as well. ${ }^{5,6}$ The increase in number of human fasciolosis and its outbreaks in the last two decades have changed the status of fasciolosis from zoonoses to an emerging health problem. ${ }^{7}$ Snails belonging to families Planorbidae and Lymnaeidae are the secondary host of Fasciola gigantica. ${ }^{5}$ Planorbidae snail Indoplanorbis exustus is acknowledged intermediate host of Fasciola gigantica in Gorakhpur, India. ${ }^{8}$

Logical approach for the fasciolosis control is to devastate the carrier snails and thus eliminate an essential link in the life cycle of the Fasciola. Use of bioactive plant molluscicides is a valuable tool in controlling the vector population as they are easily formulated, ecologically safe and culturally more acceptable than their synthetic counterpart. ${ }^{9,10}$ Chlorophyllin has natural photodynamic properties and simply extracted from various plant resources (e.g. spinach, grass, dandelion, green cabbage, water hyacinth, algae etc.). ${ }^{11,12}$ Erzinger ${ }^{13}$ has reported that photosensitive chlorophyllin show highly toxic effects against mosquito larvae in sunlight. Earlier research revealed the molluscicidal activity of chlorophyllin against L. stagnalis, Biomphalaria spp. and Physa marmorata. ${ }^{14}$ In the presence of light chlorophyllin becomes more effective and toxic. ${ }^{11,15}$ In recent times, it has been reported that chlorophyllin is a potent cercaricide against $F$. gigantica cercaria larva in sunlight. ${ }^{16}$ Previously, it has been observed that different spectral bands of the visible light stimulate the orientation and locomotion of snails towards the light source. ${ }^{17}$ It have been noted that snail Lymnaea acuminata monitor the intensity variation of visible light. ${ }^{5,18}$ Photodynamic killing of snails is one of the newly developed methods for controlling vectorborne diseases. This approach can be effectively utilized as a part of integrated approach for controlling and eliminating fasciolosis. The objective of the present study is to assess the potential efficacy of

Cite this article: Chaturvedi D, Singh DK and Singh VK. Photodynamic Toxicity of Chlorophyllin against Fasciola gigantica Carrier Snail Indoplanorbis exustus in Visible Spectral Band. Pharmacog J. 2017;9(6):729-36. 
photodynamic chlorophyllin against the snail Indoplanorbis exustus in visible spectral bands of light.

\section{MATERIALS AND METHODS}

\section{Pure Compound}

Chlorophyllin is purchased from sigma chemical Co.USA.

\section{Experimental animal}

Adult Indoplanorbis exustus ( $0.95 \pm 0.026 \mathrm{~cm}$ in length) were collected locally from Ramgarh lake and low-lying submerged fields. The animals were acclimatized for $72 \mathrm{~h}$ in laboratory condition. Experimental animals were kept in glass aquaria containing 31 of dechlorinated tap water maintained at room temperature $\left(22-25^{\circ} \mathrm{C}\right)$. The $\mathrm{pH}$ of the water was 7.1-7.3 and dissolved oxygen, free carbon dioxide and bicarbonate alkalinity were 6.5-7.1, 5.2-6.2 and 102-104 mg/l, respectively. Dead animals were removed immediately from the aquaria to avoid any contamination.

\section{Preparation of chlorophyllin}

Preparation of chlorophyllin was done according to the method of Wohllebe et al. ${ }^{19}$ as modified by Singh and Singh. ${ }^{16}$ Chlorophyll was isolated from spinach (Spinacia oleracea) using 100\% ethanol (for about $2 \mathrm{~h}$ at $55^{\circ} \mathrm{C}$ ). Then, $\mathrm{CaCO}_{3}$ (about $1 \mathrm{mg} / \mathrm{g}$ plant material) was added as a buffer, it prevents the transformation of chlorophyll into pheophytin. The extract was subsequently filtered using Whatman qualitative filter papers (Whatman International Ltd, UK) and $50 \mathrm{ml}$ petroleum benzene was added. After shaking the mixture, the chlorophyll moved into the lipophilic benzene phase. The two phases were separated in separatory funnel and about $1.0 \mathrm{ml}$ methanolic $\mathrm{KOH}$ was added to $50 \mathrm{ml}$ of the benzene phase. Upon agitation, the chlorophyll came into contact with the methanolic $\mathrm{KOH}$ and was transformed into water-soluble chlorophyllin (This process occurs due to the breakage of the ester bond between the chlorophyllin and the phytol tail by saponification). After separation of the methanolic $\mathrm{KOH}$ phase and the benzene phase most of the chlorophyllin was found in $\mathrm{KOH}$ phase. The extract was stored in a dark flask at room temperature. However, only fresh chemicals were used in the course of these experiments.

\section{Design of photo toxicity experiments}

Light experiment was set up according to the method of Tripathi et al. ${ }^{5}$ Xenon arc lamp $(500 \mathrm{~W})$ was used as visible light source. Interference colored filters was used to perform the spectral response between $400 \mathrm{~nm}$ to $650 \mathrm{~nm}$. Exposure of visible light at different wavelengths and fix intensity $\left(500 \mathrm{~W} / \mathrm{m}^{2}\right)$ was used against the chlorophyllin treated snails to observe their mortality. Toxicity experiments were done at normal room temperature $\left(22-25^{\circ} \mathrm{C}\right)$.

\section{Thin layer chromatography}

Thin layer chromatography (TLC) was performed according to the method of Barone and Tansey ${ }^{20}$ as modified by Upadhyay and Singh. ${ }^{21}$ Thin layer chromatography was carried out on $20 \times 20 \mathrm{~cm}$ precoated silica gel (Merck Specialities Private Limited, Mumbai, India) using benzene/ ethyl acetate $(9: 1, \mathrm{w} / \mathrm{v})$ as the mobile phase. The loading of extracted chlorophyllin with pure chlorophyllin were applied on TLC plates with a micropipette. TLC plates were developed with iodine vapour. Copies of chromatogram were made by tracing the plates immediately and $\mathrm{R} f$ value were calculated.

\section{High performance liquid chromatography}

Identification of active component present in chlorophyllin was done by HPLC.

\section{Sample preparation}

The sample of extracted chlorophyllin was prepared by weighing $50 \mathrm{mg}$ and then dissolving in $20 \mathrm{ml}$ of acetonitrile. The sample was properly vortexed to ensure dissolution. Prior to injected $20 \mu \mathrm{l}$ sample, the solutions was passed through a Millipore filter (ultra filter disc $3 \mathrm{~K} 43$ $\mathrm{mm} 10 \mathrm{pk}$, Cole Parmer, Germany) to remove any undissolved particles.

\section{Preparation of standard solution}

Pure standard solution of chlorophyllin was prepared by diluting $10 \mathrm{mg}$ chlorophyllin in $20 \mathrm{ml}$ of acetonitrile. The mixture was vortexed to ensure proper dissolution of pure compound. The solution, thus obtained, was passed through Millipore filter (ultra filter disc $3 \mathrm{~K} 43 \mathrm{~mm} 10 \mathrm{pk}$, Cole Parmer, Germany).

\section{Instrumentation}

The HPLC system was equipped with two LC- 10ATVP pumps, a Cecil CE 4201 UV- variable detector and a Microliter $\# 702$ (Hamilton-Bonaduz, Schweiz) syringe with a loop size of $20 \mu \mathrm{l}$. Reverse-phase chromatographic analysis was carried out under isocratic conditions using a reverse-phase Luna $5 \mu \mathrm{C}_{18}$ Phenomenex column $(250 \times 4.6 \mathrm{~mm})$ at $27^{\circ} \mathrm{C}$. Acetonitrile (HPLC grade) was used as the mobile phase solvent under a pressure of $260-270 \mathrm{Kgf} / \mathrm{cm}^{2}$ and run time of $15 \mathrm{~min}$. The analysis was carried out a flow rate of one $\mathrm{ml} / \mathrm{min}$., the extracted chlorophyllin effluent being monitored at $220 \mathrm{~nm}$. Data acquisition were done with Power Stream ${ }^{\mathrm{TM}}$ software.

\section{Treatment protocol for concentration-response relationship}

Toxicity experiments were done according to the method of Singh and Agarwal. ${ }^{22} \mathrm{~A}$ total of 10 snails were placed in a glass aquarium containing 31 of dechlorinated tap water. Snails were treated with different concentrations of extracted and pure chlorophyllin and incubated for $4 \mathrm{~h}$ in darkness. Thereafter, in I set of experiment the extracted and pure chlorophyllin treated snails were exposed to sunlight. In II set of experiment extracted chlorophyllin treated snails were exposed to different spectral band of monochromatic visible light. The control animals were kept in the equal volume of water under similar conditions without treatment. In control group, I snails were exposed to sunlight without any treatment. In control group II snails were exposed to monochromatic visible lights without any treatment. Each experiment was replicated 6 times. Mortality of snails was recorded at $24 \mathrm{~h}$ up to $96 \mathrm{~h}$. The dead animals were removed immediately to avoid any contamination in aquarium water. The mortality of snails was established by the contraction of body within the shell, no response to needle probe was taken as evidence of death.

Concentration mortality data for each group of snails were analyzed using the probit log analysis program, POLO-PC (LeOra Software) Robertson et al. ${ }^{23}$ to estimate the $\mathrm{LC}_{50}$ of extracted chlorophyllin and the 95\% confidence intervals for these concentrations. The slope of the probit lines was also estimated. This program ran chi-square test for goodness of fit of the data to the probit model. If the model fits, the calculated value of chi-square is less than the chi-square table value for the appropriate degrees of freedom. If the model does not fit, the $\mathrm{LC}_{50}$ value for the particular population may not be reliably estimated and is adjusted with the heterogeneity factor (Observed chi-square values divided degrees of freedom). This program uses heterogeneity factor as a correlation factor when the value of Pearson's chi-square statistic is significant as $\mathrm{P}<0.05$. The index of significance for potency estimation (g-value) was used to calculate 95\% confidence intervals for potency (relative potency is equivalent to tolerance ratio). Parallelism of the probit regression lines implies a constant relative potency at all levels of response. POLO-PC was used to test equality and parallelism of 
the slope of the probit lines Robertson et al. ${ }^{23}$ The regression coefficient between exposure time and different values of $\mathrm{LC}_{50}$ was determined by the method of Sokal and Rohlf. ${ }^{24}$

\section{RESULTS}

The molluscicidal activity of extracted/pure chlorophyllin was tested at different time of exposure to various light spectra and chlorophyllin concentration against the pest Indoplanorbis exustus (Table 1). A significant $(\mathrm{p}<0.05)$ negative regression was noted in between the exposure time and $\mathrm{LC}_{50}$ of the treatments (Table 2). The $\mathrm{LC}_{50}$ at $96 \mathrm{~h}$ of pure and extracted chlorophyllin was $6.54 \mathrm{mg} / \mathrm{l}$ and $939.65 \mathrm{mg} / \mathrm{l}$ in sunlight (Table 2). Toxicity was noted in the presence of visible spectral band of lights at fix intensity $\left(500 \mathrm{~W} / \mathrm{m}^{2}\right)$. The highest toxicity was noted in yellow light $\left(\mathrm{LC}_{50}\right.$ at $\left.96 \mathrm{~h}: 2016.79 \mathrm{mg} / \mathrm{l}\right)$ and lowest in green light $\left(\mathrm{LC}_{50}\right.$ at $96 \mathrm{~h}$ : $2433.16 \mathrm{mg} / \mathrm{l}$ ) (Table 3).

The thin layer chromatography analysis demonstrated that the $\mathrm{R} f$ value of extracted chlorophyllin (0.50) was nearly equivalent to the $\mathrm{R} f$ value of pure chlorophyllin (0.48). The identification of active components was done by comparing the retention time $\left(\mathrm{R}_{\mathrm{t}}\right)$ and chromatographic peaks of extracted chlorophyllin and pure chlorophyllin. The HPLC fingerprint profile of the extracted chlorophyllin showed major peaks at the retention time of $10.89 \mathrm{~min}$. (Figure 2) whereas the pure standard solutions of chlorophyllin showed major peaks at the retention time of $1.74 \mathrm{~min}$. (Figure 3).

The slope values given in Tables 2 and 3 were steep and separate estimates of LC based on each of six replicates were found to be within the $95 \%$ confidence limits of $\mathrm{LC}_{50}$. The t-ratio was higher than 1.96 and heterogeneity factor was less than 1.0. The g-value was less than 0.5 at all probability levels (90, 95 and 99 respectively) (Tables 2 and 3). There was significant negative regression $(\mathrm{p}<0.05)$ between the exposure time and $\mathrm{LC}_{50}$ of the treatments (Tables 2 and 3 ).

\section{DISCUSSION}

The data given above indicate that chlorophyllin pure/extracted from spinach is very effective and efficient molluscicide. Toxicity against the snail Indoplanorbis exustus is time and concentration dependent as evident by the negative regression between exposure period and $\mathrm{LC}_{50}$ values of the different treatments. Toxicity of photodynamic chlorophyllin is noted against $I$. exustus in the occurrence of different visible spectral bands of lights at a fix intensity of $500 \mathrm{~W} / \mathrm{m}^{2}$. All the monochromatic visible lights have adequate energy to elicit the response of photodynamic chlorophyllin. Yellow light caused higher toxicity of chlorophyllin against snails than other monochromatic visible lights. Significant variation in toxicity of chlorophyllin exposed to same intensity of visible monochromatic light is evident from different $\mathrm{LC}_{50}$ of chlorophyllin. All lights have different wavelengths and it represents that variation in wavelength of light has significant effect on mortality, as evident from highest toxicity of chlorophyllin was observed in yellow light $\left(\mathrm{LC}_{50}\right.$ at $\left.96 \mathrm{~h}: 2016.79 \mathrm{mg} / \mathrm{l}\right)$ and lowest in green light ( $\mathrm{LC}_{50}$ at $\left.96 \mathrm{~h}: 2433.16 \mathrm{mg} / \mathrm{l}\right)$.

Recently, Singh and Singh ${ }^{16}$ demonstrated the larvicidal activity of chlorophyllin against $F$. gigantica at the fix intensity of $300 \mathrm{~W} / \mathrm{m}^{2}$. The

Table 1: Concentration of extracted and pure chlorophyllin used in toxicity experiment against Indoplanorbis exustus

\begin{tabular}{ccc}
\hline Experimental condition & Chemical & Concentration $(\mathrm{mg} / \mathrm{l})$ \\
\hline Sunlight & Ext Chl & $900,1000,1100,1200$ \\
& Pure Chl & $10,20,30,40$ \\
Different spectra of light & Ext Chl & $1900,2100,2300,2500$ \\
\hline
\end{tabular}

Abbreviation: Ext- Extracted, Chl- Chlorophyllin effectiveness of chlorophyllin depends on light attenuation in the water body. ${ }^{25}$ Relating to attenuation it was tested earlier that about $36 \mathrm{~W} / \mathrm{m}^{2}$ of visible day light are sufficient to stimulate photodynamic destruction of Chaoborus crystallinus larvae. ${ }^{26}$ The time-dependent toxic effect of tested plant products may be due to the uptake of active compound by the snails, which progressively accumulated in the body with an increase exposure period. It is also possible that the active compound could change into more toxic forms in the aquarium water or in the snail's body in visible band spectra of light.

When sunlight penetrates water at a marked angle then longer visible wavelength are absorbed more by water than shorter visible wavelengths during penetration..$^{27,16}$ The toxicity experiments clearly demonstrated that pure chlorophyllin is more toxic than extracted chlorophyllin and chlorophyllin become more effective in sunlight than different spectral band of monochromatic visible lights. It may be due to higher solubilized atom of chlorophyllin in sunlight transferred its excitation energy to oxygen, which generate singlet oxygen and other reactive oxygen species (ROS), which have the potential to kill the vector organism..$^{28,29,15}$ ROS caused strong oxidative stress to the cells which damage the cell membrane, protein, DNA and other cell structures. ${ }^{30,31}$ Photodynamic chlorophyllin was capable to kill mosquito larvae and other small animals within a few hours in sunlight. ${ }^{11}$ Recent research on chlorophyllin has been advocated by researchers. As Erzinger et al. ${ }^{32}$ demonstrated that photodynamic chlorophyllin was able to kill four different species, a small crustacean (Daphnia similis), a unicellular alga (Euglena gracilis) and two species of fish (Astyanax bimaculatus and Cyprynus carpio) which are the vector of parasitic diseases. Earlier, Kumar and Singh ${ }^{33}$ reported that chlorophyllin show toxic effects against Lymnaea acuminata in the presence of red visible light and sunlight. Recently, Hader et al. ${ }^{15}$ reported the toxicity of photodynamically active chlorophyllin against fish ectoparasite Ichthiophthirius multifiliis, Ichtyobodo, Dactylogyrus, Trichodina, Argulus.

The steep slope indicates that a small increase in the concentration of molluscicide caused higher mortality. The t-ratio value greater than 1.96 indicates that the regression is significant $(p<0.05)$. The heterogeneity factor value less than 1.0 denotes that in the replicate test of random samples; the concentration response is limited and thus the model fits the data adequately. The index of significance of the potency estimation $\mathrm{g}$ indicates that the value of the mean is within the limit at all probability levels (90, 95 and 99 respectively) since it is less than 0.5 .

Thin layer chromatography (TLC) study demonstrates the preliminary identification of the active components in extracted and pure chlorophyllin. The co-migration of extracted and pure chlorophyllin on TLC plate show nearly equivalent $\mathrm{R} f$ value of extracted (0.50) and pure (0.48) chlorophyllin. The stationary phase, silica gel can be considered polar while the organic solvent used as the mobile phase is non-polar. ${ }^{34}$ Components of mixture differ in polarity and have different tendencies to absorb onto the silica gel or dissolve in the organic solvent. ${ }^{35}$ The more polar components have a stronger interaction with the silica gel and absorb on the silica gel strongly, therefore, less distance it can travel up the plate and show lower $\mathrm{R} f$ value. In contrast, non-polar components move higher up the plate and show higher $\mathrm{R} f$ value. ${ }^{34,35}$

High performance liquid chromatography (HPLC) has already been considered to be the simplest and most reproducible technique for analyzing complex mixtures of pigments in food and other sources. HPLC fingerprinting is the best way for chemical characterization. ${ }^{36}$

Willstatter and Escher ${ }^{37}$ discovered that chlorophyll was a mixture of two compounds which were designated as chlorophyll a and chlorophyll b. Chlorophyll a contains $-\mathrm{CH}_{3}$ group and chlorophyll b contain $-\mathrm{CHO}$ group, respectively and after removal of phytol tail chlorophyll converts into chlorophyllin (Figure 1) ${ }^{38}$ It was reported by Lim, ${ }^{39}$ that the replace- 
Table 2: Toxicity of extracted and pure chlorophyllin in sunlight against Indoplanorbis exustus

\begin{tabular}{ccccccccc}
\hline $\begin{array}{c}\text { Exposure } \\
\text { Period }\end{array}$ & Treatment & $\begin{array}{c}\mathrm{LC}_{50} \mathrm{mg} / \mathrm{l} \\
(\mathrm{w} / \mathrm{v})\end{array}$ & $\mathrm{LCL}$ & $\mathrm{UCL}$ & Slope value & t-ratio & g-value & Heterogeneity \\
\hline \multirow{2}{*}{$24 \mathrm{~h}$} & Ext Chl & 1371.59 & 1232.31 & 2020.21 & $6.68 \pm 2.03$ & 3.28 & 0.35 & 0.15 \\
& Pure Chl & 37.22 & 29.69 & 56.54 & $1.87 \pm 0.40$ & 4.64 & 0.17 & 0.23 \\
\multirow{3}{*}{$48 \mathrm{~h}$} & Ext Chl & 1187.43 & 1118.12 & 1364.55 & $7.28 \pm 1.85$ & 3.91 & 0.25 & 0.16 \\
& Pure Chl & 22.57 & 16.97 & 30.24 & $1.48 \pm 0.37$ & 3.99 & 0.24 & 0.25 \\
$72 \mathrm{~h}$ & Ext Chl & 1028.96 & 964.45 & 1088.74 & $7.13 \pm 1.79$ & 3.97 & 0.24 & 0.17 \\
& Pure Chl & 15.70 & 11.03 & 19.57 & $1.75 \pm 0.37$ & 4.65 & 0.17 & 0.64 \\
& Ext Chl & 939.65 & 883.78 & 976.62 & $11.35 \pm 1.99$ & 5.69 & 0.11 & 0.44 \\
& Pure Chl & 6.54 & 2.54 & 9.66 & $1.85 \pm 0.43$ & 4.28 & 0.20 & 0.35 \\
\hline
\end{tabular}

Six batches of ten snails were exposed to different concentration. Mortality was determined at $24 \mathrm{~h}$ to $96 \mathrm{~h}$. Concentrations given are the final concentration (w/v) in the glass aquarium water. Abbreviation: Ext- Extracted, Chl- Chlorophyllin, LCL- Lower confidence limit, UCL-Upper confidence limit. Significant negative regression $(\mathrm{p}<0.05)$ was observed between exposure time and $\mathrm{LC}_{50}$ treatments. Ts - testing significant of the regression coefficient- Ext Chl $-8.804^{+}$to $-3.315^{+}$and $102.8^{++}$to $2155^{++}$and Pure Chl $-0.6134^{+}$to $-0.2108^{+}$and $0.0^{++}$to $90.37^{++}$was observed. ${ }^{+}$Linear regression between $\mathrm{X}$ and $\mathrm{Y}$. ${ }^{++}$Non- linear regression between $\mathrm{X}$ and $\mathrm{Y}$.

Table 3: Toxicity of extracted chlorophyllin in the presence of different spectra of light against Indoplanorbis exustus

\begin{tabular}{|c|c|c|c|c|c|c|c|c|c|}
\hline $\begin{array}{l}\text { Exposure } \\
\text { period }\end{array}$ & Treatment & $\begin{array}{c}\text { Different spectra } \\
\text { of light }\end{array}$ & $\begin{array}{l}\mathrm{LC}_{50} \mathrm{mg} / \mathrm{l} \\
(\mathrm{w} / \mathrm{v})\end{array}$ & LCL & UCL & Slope values & t-ratio & g-value & Heterogeneity \\
\hline \multirow{7}{*}{$24 \mathrm{~h}$} & \multirow{7}{*}{ Ext Chl } & Green & 2844.62 & 2612.40 & 3628.83 & $9.99 \pm 2.60$ & 3.83 & 0.26 & 0.38 \\
\hline & & Violet & 2739.81 & 2554.34 & 3259.69 & $10.43 \pm 2.46$ & 4.23 & 0.21 & 0.32 \\
\hline & & Blue & 2592.33 & 2592.33 & 2866.12 & $11.66 \pm 2.34$ & 4.98 & 0.15 & 0.26 \\
\hline & & Orange & 2548.53 & 2415.69 & 2851.25 & $9.67 \pm 2.10$ & 4.59 & 0.18 & 0.29 \\
\hline & & Red & 2440.94 & 2330.23 & 2663.53 & $9.35 \pm 2.00$ & 4.67 & 0.17 & 0.26 \\
\hline & & White & 2320.46 & 2233.79 & 2451.60 & $10.11 \pm 1.97$ & 5.13 & 0.14 & 0.15 \\
\hline & & Yellow & 2235.96 & 2171.54 & 2309.26 & $13.46 \pm 2.04$ & 6.59 & 0.08 & 0.17 \\
\hline \multirow{7}{*}{$48 \mathrm{~h}$} & \multirow{7}{*}{ Ext Chl } & Green & 2760.96 & 2520.88 & 3734.57 & $7.16 \pm 2.09$ & 3.41 & 0.32 & 0.17 \\
\hline & & Violet & 2681.70 & 2480.02 & 3360.56 & $7.61 \pm 2.06$ & 3.68 & 0.28 & 0.20 \\
\hline & & Blue & 2464.91 & 2351.45 & 2697.30 & $9.59 \pm 2.03$ & 4.72 & 0.17 & 0.17 \\
\hline & & Orange & 2387.51 & 2291.20 & 2557.41 & $9.91 \pm 1.99$ & 4.96 & 0.15 & 0.26 \\
\hline & & Red & 2299.50 & 2220.64 & 2409.02 & $11.03 \pm 1.99$ & 5.54 & 0.12 & 0.26 \\
\hline & & White & 2178.42 & 2097.68 & 2259.46 & $10.95 \pm 1.95$ & 5.60 & 0.12 & 0.20 \\
\hline & & Yellow & 2151.63 & 2082.41 & 2217.12 & $13.13 \pm 2.02$ & 6.49 & 0.09 & 0.29 \\
\hline \multirow{7}{*}{$72 \mathrm{~h}$} & \multirow{7}{*}{ Ext Chl } & Green & 2588.50 & 2408.73 & 3189.62 & $7.04 \pm 1.98$ & 3.54 & 0.30 & 0.13 \\
\hline & & Violet & 2520.12 & 2379.55 & 2870.95 & $8.32 \pm 2.00$ & 4.15 & 0.22 & 0.19 \\
\hline & & Blue & 2355.48 & 2263.03 & 2509.11 & $9.84 \pm 1.97$ & 4.98 & 0.15 & 0.13 \\
\hline & & Orange & 2274.73 & 2185.51 & 2398.54 & $9.47 \pm 1.93$ & 4.90 & 0.15 & 0.26 \\
\hline & & Red & 2172.88 & 2092.68 & 2252.28 & $11.08 \pm 1.96$ & 5.64 & 0.12 & 0.31 \\
\hline & & White & 2117.44 & 2034.18 & 2189.05 & $11.58 \pm 1.97$ & 5.85 & 0.11 & 0.22 \\
\hline & & Yellow & 2075.05 & 2003.81 & 2133.92 & $14.33 \pm 2.09$ & 6.84 & 0.08 & 0.33 \\
\hline \multirow{7}{*}{$96 \mathrm{~h}$} & \multirow{7}{*}{ Ext Chl } & Green & 2433.16 & 2295.35 & 2792.54 & $6.99 \pm 1.90$ & 3.66 & 0.28 & 0.22 \\
\hline & & Violet & 2380.57 & 2241.28 & 2747.46 & $6.30 \pm 1.88$ & 3.33 & 0.34 & 0.11 \\
\hline & & Blue & 2223.19 & 2139.50 & 2320.09 & $10.18 \pm 1.93$ & 5.25 & 0.13 & 0.17 \\
\hline & & Orange & 2125.44 & 2029.61 & 2207.68 & $10.08 \pm 1.94$ & 5.19 & 0.14 & 0.29 \\
\hline & & Red & 2089.26 & 2005.03 & 2157.85 & $12.00 \pm 2.00$ & 5.99 & 0.10 & 0.23 \\
\hline & & White & 2029.92 & 1946.67 & 2092.65 & $13.62 \pm 2.11$ & 6.44 & 0.09 & 0.39 \\
\hline & & Yellow & 2016.79 & 1950.42 & 2069.14 & $17.05 \pm 2.33$ & 7.30 & 0.07 & 0.44 \\
\hline
\end{tabular}

Six batches of ten snails were exposed to different concentration. Mortality was determined at every $24 \mathrm{~h}$ up to $96 \mathrm{~h}$. Concentrations given are the final concentration (w/v) in the glass aquarium water. Abbreviation: Ext- Extracted, Chl- Chlorophyllin, LCL- Lower confidence limit, UCL-Upper confidence limit. Significant negative regression ( $\mathrm{p}<0.05$ ) was observed between exposure time and $\mathrm{LC}_{50}$ of treatments. Ts - testing significant of the regression coefficient of Green light $-10.11^{+}$to $-2.93^{+}$and $1531^{++}$to $3750^{++}$, Violet light $-6.90^{+}$to $-2.10^{+}$and $1805^{++}$to $3350^{++}$, Blue light $-5.60^{+}$to $-4.53^{+}$and $1557^{++}$to $3256^{++}$, Orange light $-6.88^{+}$to $-4.63^{+}$ and $1365^{++}$to $3297^{++}$, Red light $-6.60^{+}$to $-3.24^{+}$and $1418^{++}$to $3078^{++}$, White light $-5.94^{+}$to $-1.82^{+}$and $1479^{++}$to $2814^{++}$, Yellow light $-3.81^{+}$to $-2.30^{+}$and $1589^{++}$to $2627^{++}$ was observed. ${ }^{+}$Linear regression between $\mathrm{X}$ and $\mathrm{Y} .{ }^{++}$Non- linear regression between $\mathrm{X}$ and $\mathrm{Y}$. 

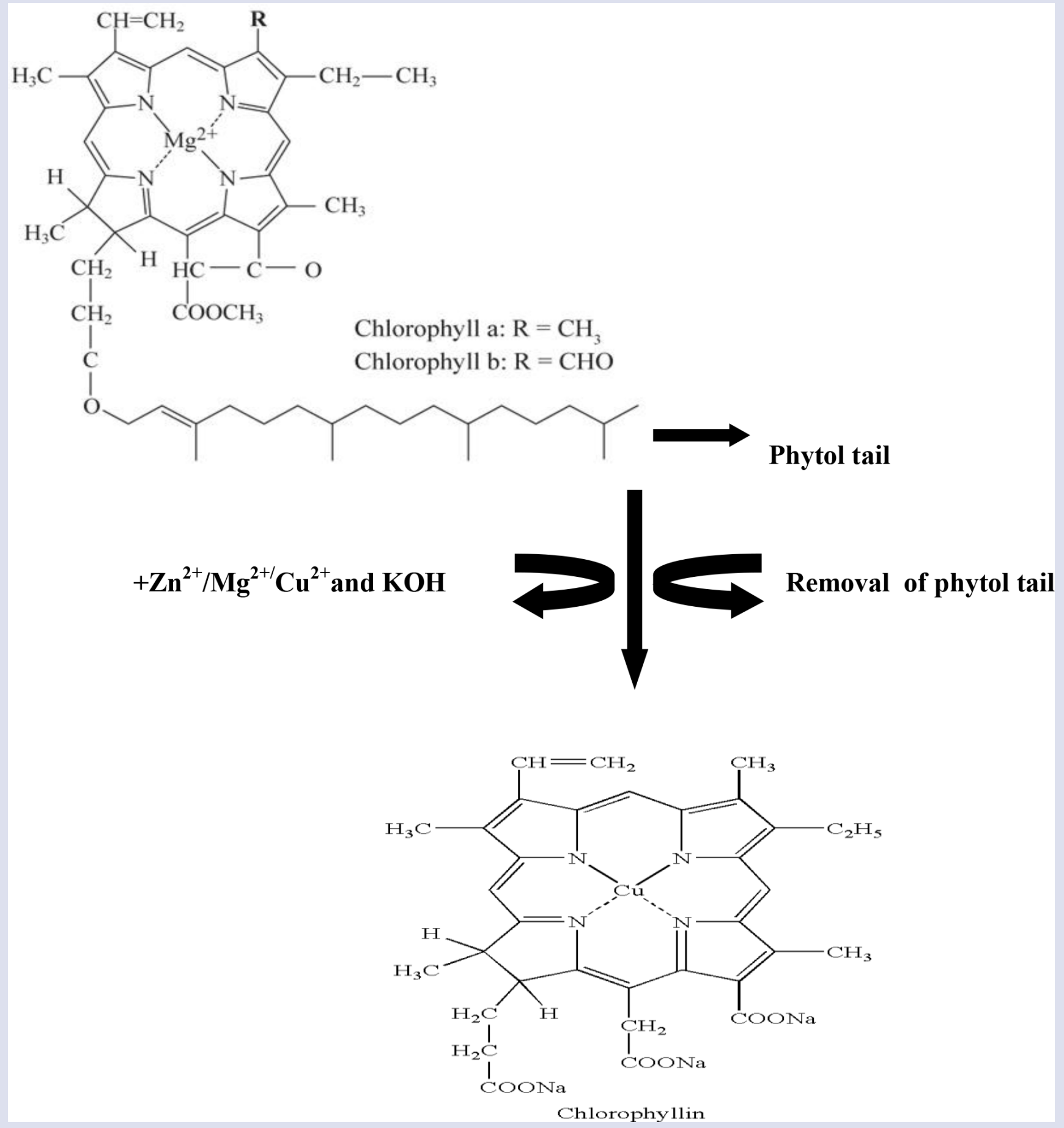

Figure 1: Transformation of chlorophyll in chlorophyllin from spinach (Spinacia oleracea). 


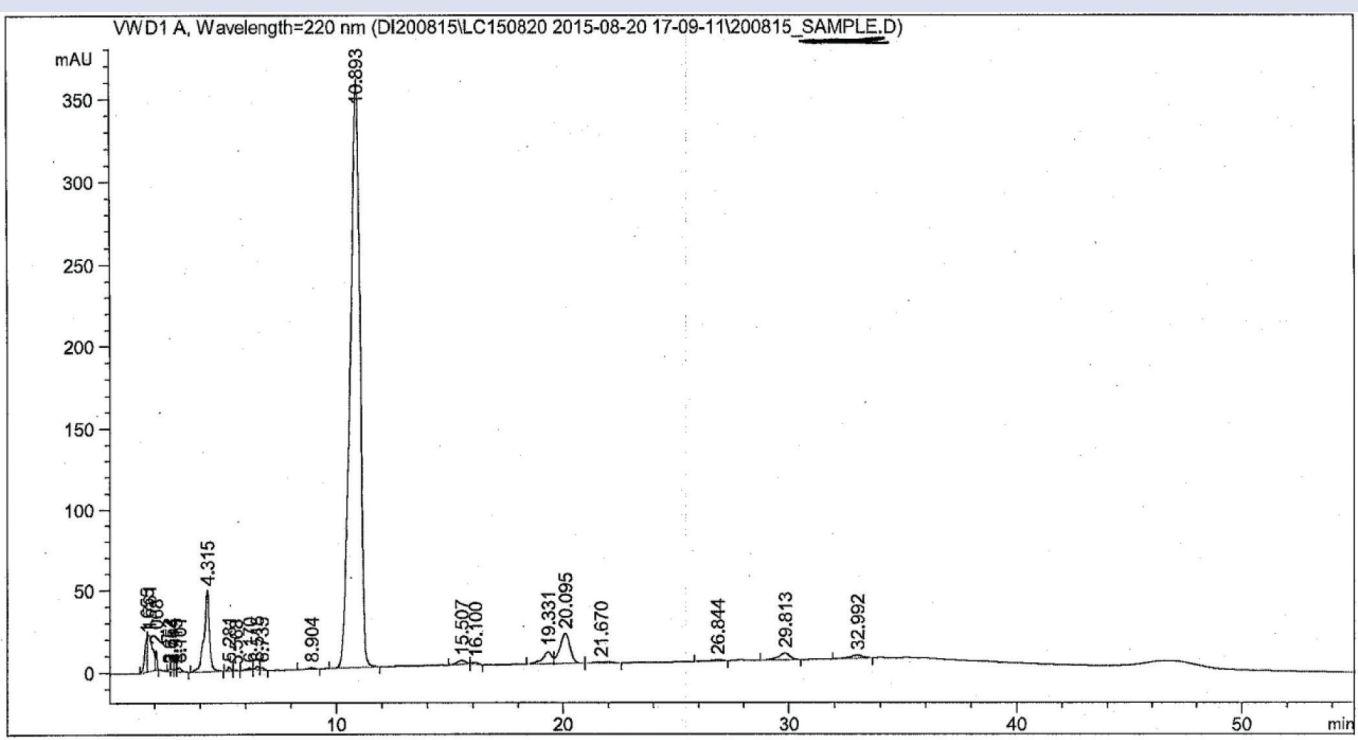

\begin{tabular}{clcccccc}
\hline $\begin{array}{c}\text { Peak } \\
\#\end{array}$ & Peak Name & $\begin{array}{c}\text { Ret. Time } \\
{[\mathrm{min}]}\end{array}$ & Type & $\begin{array}{c}\text { Width } \\
{[\mathrm{min}]}\end{array}$ & $\begin{array}{c}\text { Area } \\
{\left[\mathrm{mAU}^{*} \mathrm{~s}\right]}\end{array}$ & $\begin{array}{c}\text { Height } \\
{[\mathrm{mAU}]}\end{array}$ & $\begin{array}{c}\text { Area } \\
{[\%]}\end{array}$ \\
\hline 1 & Chlorophyllin b & 1.76 & $\mathrm{VV}$ & 0.20 & 335.47 & 21.79 & 2.51 \\
2 & Chlorophyllin a & 10.89 & $\mathrm{BB}$ & 0.42 & 1.06 & 359.60 & 79.98 \\
\hline
\end{tabular}

Figure 2: High Performance Liquid Chromatography of extracted chlorophyllin.

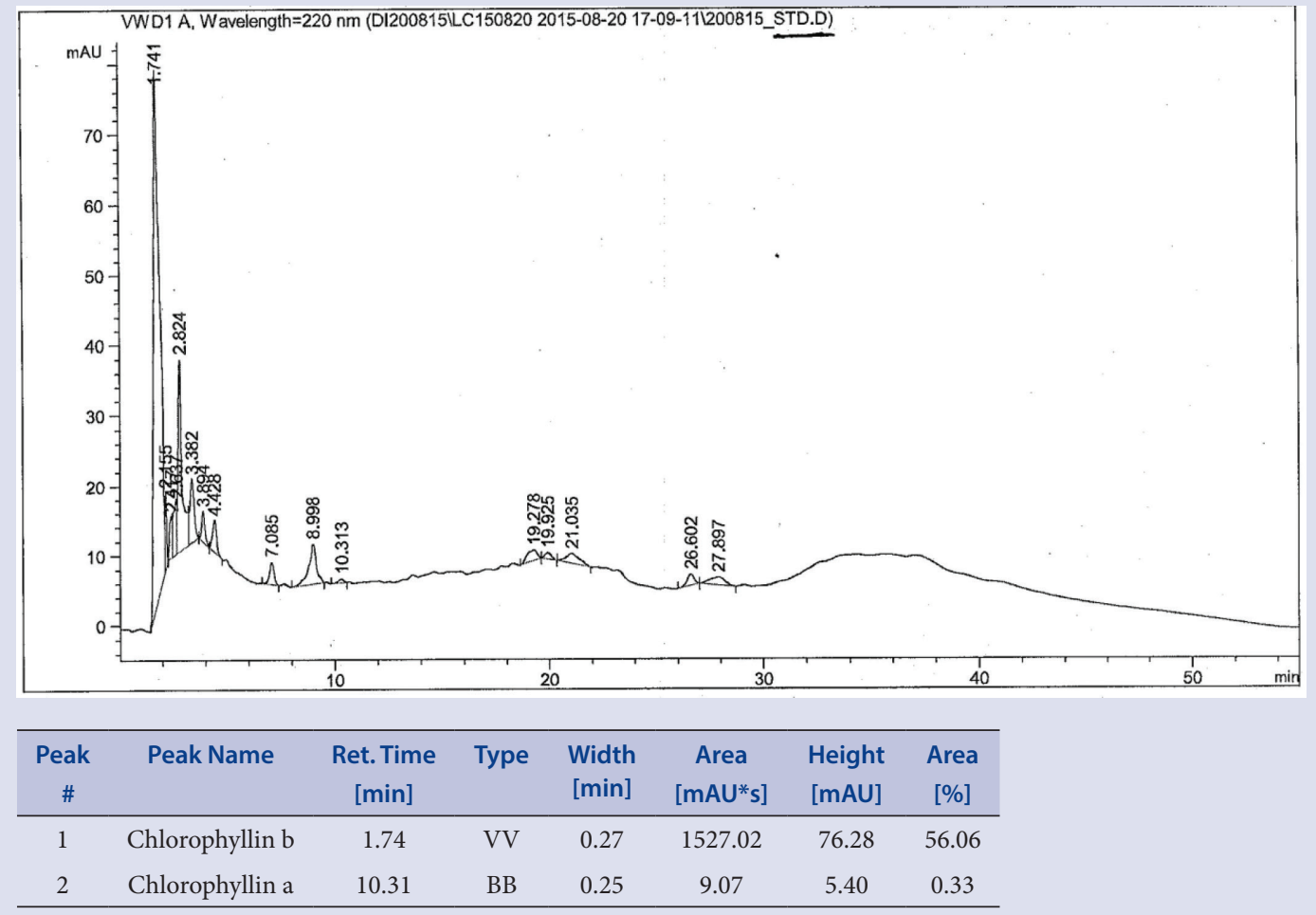

Figure 3: High Performance Liquid Chromatography of pure chlorophyllin. 
ment of $-\mathrm{CH}_{3}$ group (in chlorophyll a) with $-\mathrm{CHO}$ group (in chlorophyll b) at the position C-7 increases the polarity of the chlorophyll b; since chlorophyll b becomes more polar than chlorophyll a and appears on the shorter retention time. It was also reported that the retention time always decreases in the same order (pheophytin a $>$ chlorophyll a > pheophytin $\mathrm{b}>$ chlorophyll $\mathrm{b}>$ chlorophyllide $\mathrm{a}>$ chlorophyllide $\mathrm{b}$ ) and predominantly depends on the polarity of the mobile phase. ${ }^{39,40}$ In the present study the separation of chlorophyll derivates by HPLC method clearly demonstrate the major peaks at the retention time of $10.89 \mathrm{~min}$. in extracted chlorophyllin and $1.74 \mathrm{~min}$. in pure standard chlorophyllin. From the above reporting, it can be state that higher retention time indicates the presence of chlorophyllin a in extracted chlorophyllin ${ }^{41,42}$ and comparatively lower retention time indicates the presence of chlorophyllin $\mathrm{b}$ in pure chlorophyllin. In present observation, major peaks of the retention time of chlorophyllin a and b clearly demonstrate that these are the active components which are found more abundantly in extracted and pure chlorophyllin, respectively. Now, the HPLC data clearly define the minor differences between the $\mathrm{R} f$ values of TLC results. It can also be concluded that the toxicity of extracted chlorophyllin is due to chlorophyllin a than chlorophyllin $\mathrm{b}$.

\section{CONCLUSION}

The laboratory studies reported in this work demonstrate that photodynamic chlorophyllin is very powerful and adequate molluscicide for target vector snails. It can be avowed that molluscicidal activity of chlorophyllin is due to their active components: chlorophyllin a and b. Such type of exploratory research work by means of plant extracts can be effective approach to kill the snail population. Being economically and environmentally friendly, this approach can get high public acceptance also. Photodynamic chlorophyllin as a molluscicide show great potential of photosensitization prospective for the control of endemic fasciolosis in developing countries.

\section{ACKNOWLEDGEMENT}

The authors are grateful to Prof. D. K. Singh (Department of Zoology, DDU Gorakhpur University, Gorakhpur, India) for his valuable suggestions in analysis and interpretation of data and preparation of the final manuscript.

\section{CONFLICTS OF INTEREST}

We declare that we have no conflict of interest.

\section{ABBREVIATIONS USED}

TLC: Thin Layer Chromatography; HPLC: High Performance Liquid Chromatography; Ext: Extracted; Chl: Chlorophyllin.

\section{REFERENCES}

1. Ashrafi K, Bargues MD, O'Neill S, Mas-Coma S. Fascioliasis: a worldwide parasitic disease of importance in travel medicine. Travel Med Infect Dis. 2014;12(6):636-49

2. Singh DJ, Singh DK. Anthelmintic activity of chlorophyllin against different larval stages of Fasciola gigantica. Rev Inst Med Trop Sao Paulo. 2016:58:39.

3. Cwiklinski K, Allen K, LaCourse J, Williams DJ, Paterson S, Hodgkinson JE. Characterization of a novel panel of polymorphic microsatellite loci for the liver fluke, Fasciola hepatica, using next generation sequencing approach. Infect Genet Evol. 2015;32:298-304.

4. Singh O, Agarwal RA. Toxicity of certain pesticides to two economic species of snails in Northern India. J Econ Entomol. 1981;74(5):568-71.

5. Tripathi AP, Singh VK, Singh DK. Orientation of the snail Lymnaea acuminata to different wavelength of visible light. The Ecoscan. 2013;4:235-40.

6. Sunita K, Habib M, Kumar P, Singh VK, Husain SK, Singh DK. Inhibition of acetylcholinesterase and cytochrome oxidase activity in Fasciola gigantica cercaria by phytoconstituents. Acta Tropica. 2016;154:19-24.
7. Nyindo M, Lukambagire A. Fasciolosis: An ongoing zoonotic trematode infection. Biomed Res Int Volume. 2015(2015), Article ID786195, pages 8.

8. Soni N, Singh VK. Molluscicidal activity of Tamarindus indica and Terminalia arjuna against Indoplanorbis exustus: A causative agent of Trematodiasis. Sci Agric. 2015;12:163-70.

9. Soni N, Singh DK, Singh VK. Inhibition kinetics of acetylcholinesterase and phosphatase by the active constituents of Terminalia arjuna and Tamarindus indica in the cerebral ganglion of Lymnaea acuminata. Pharmacogn J. 2017;9(2):98-101.

10. Tekwu EM, Bosompem KM, Anyan WK, Appiah-Opong R, Owusu KB, Tettey MD. In vitro assessment of anthelmintic activities of Rauwolfia vomitoria (Apocynaceae) stem bark and roots against parasitic stages of Schistosoma mansoni and Cytotoxic Study. J Parasitol Res Volume. 2017 (2017), Article ID 2583969, 11 pages.

11. Wohllebe S, Richter R, Richter P, Hader DP. Photodynamic control of human pathogenic parasites in aquatic ecosystems using chlorophyllin and pheophorbid as photodynamic substances. Parasitol Res. 2009;104(3):593-600.

12. Singh DJ, Singh DK. Phytotherapy of chlorophyllin exposed Lymnaea acuminata: A new biotechnological tool for fasciolosis control. Parasite Epidemiol Control. 2016;1(2):20-5.

13. Erzinger GS. New perspectives for the control of parasitic diseases through the use of photodynamic products. Pharma Anal Acta. 2011;9:1-3.

14. Mahmoud MS, Richter P, Shalaby HAM, Kandil OM, Hader DP. Molluscicidal activity of chlorophyll extraction against the freshwater snails. J Coastal Life Med. 2013;1:85-8

15. Hader DP, Schmidl J, Hilbig R, Oberle M, Wedekind H, Richter P. Fighting fish parasites with photodynamically active chlorophyllin. Parasitol Res. 2016;115(6):2277-83.

16. Singh DJ, Singh DK. Toxicity of chlorophyllin in different wavelengths of visible light against Fasciola gigantica larvae. J Photochem Photobiol B: Biol. 2015;144:57-60.

17. Sakakibara M, Aritaka T, lizuka A, Suzuki H, Horikoshi T, Lukowiak K. Electrophysiological responses to light of neurons in the eye and statocyst of Lymnaea stagnalis. J Neurophysiol. 2005;93(1):493-507.

18. Tripathi AP, Singh VK, Singh DK. Attraction of Lymnaea acuminata against the visible photo stimulant: A new tool in fasciolosis control. Research. 2014;1:743.

19. Wohllebe S, Ulbrich C, Grimm D, Pietsch J, Erzinger G, Richter R. Photodynamic treatment of Chaoborus crystallinus larvae with chlorophyllin induces necrosis and apoptosis. Photochem Photobiol. 2011;87(5):1113-22.

20. Barone FE, Tansey MK. Isolation, purification, identification, synthesis and kinetics of activity of the anticandial component of Allium sativum and hypothesis for its mode of action. Mycologia. 1977;88:793-825.

21. Upadhyay A, Singh DK. Molluscicidal activity of Sapindus mukorossi and Terminalia chebula against the freshwater snail Lymnaea acuminata. Chemosphere. 2011;83(4):468-74

22. Singh DK, Agarwal RA. Correlation of the anticholinesterase and molluscicidal activity of the latex of Euphorbia royleana Bioss. on Lymnaea acuminata. J Nat Prod. 1984;47(4):702-5.

23. Robertson JL, Russell RM, Preisler HK, Savin NE. Bioassay with arthropods, POLO computer programme for analysis of bioassay data. $2^{\text {nd }}$ ed. Boca Raton: CRC Press 2007;1-224.

24. Sokal RR, Rohlf FJ. Introduction to biostatistics. San Francisco; W.H. Freeman and Co. 1996;271-73.

25. DeRosa MC, Crutchley RJ. Photosensitized singlet oxygen and its applications Coord Chem Rev. 2002;233:234:351-71.

26. Erzinger GS, Wohllebe S, Vollrath F, Souza SC, Richter P, Lebert M. Optimizing conditions for the use of chlorophyll derivatives for photodynamic control of parasites in aquatic ecosystems. Parasitol Res. 2011;109(3):781-6.

27. Vanderstaete J, Goossens R, Ghabour JK. Bathymetric mapping of coral reefs in the red sea (Hurghada-Egypt) using LANDSTAT7 ETM+DATA, seventh international conference on remote sensing for marine and coastal environments Miami, Florida, 20-22 May, 2002.

28. Tominaga H, Kodama S, Matsuda N, Suzuki K, Watanabe M. Involvement of reactive oxygen species (ROS) in the induction of genetic instability by radiation. J Radiat Res. 2004;45(2):181-8.

29. Richter PR, Strauch SM, Azizullah A, Hader DP. Chlorophyllin as a possible measure against vectors of human parasites and fish parasites. Front Environ Sci. 2014;2:1-6.

30. Kohen R, Nyska A. Oxidation of biological system: oxidative stress phenomena, antioxidants, redox reactions, and methods for their quantification. Toxico Pathol. 2002;30(6):620-50.

31. Singh K, Singh VK. Anti-reproductive activity of chlorophyllin on fresh water snail Lymnaea acuminata. Res J Parasitol. 2015;10:160-6.

32. Erzinger GS, Souza SC, Pinto LH, Hoppe R, Del-Ciampo LF, Souza O, et al. Assessment of the impact of chlorophyll derivatives to control parasites in aquatic ecosystems. Ecotoxicol. 2015;24(4):949-58.

33. Kumar N, Singh VK. Bait formulations of chlorophyllin against infected/uninfected Lymnaea acuminata in red and sunlight. Int J Zool Res. 2015;11(5):207-14.

34. Sasidharan S, Chen Y, Saravanan D, Sundram KM, Latha LY. Extraction, Isolation and characterization of bioactive compounds from plants' extracts. A J T C A 
M. 2011;8(1):1-10.

35. Lu J, Ma HY, Zhang W, Ma ZG, Yao S. Separation of berberine hydrochloride and tetrahydropalmatine and their quantitative analysis with thin layer chromatography involved with ionic liquids. J Anal Methods Chem. 2015; Volume 2015, article ID 642401, 7 pages.

36. Springfield EP, Eagles PKF, Scott G. Qualitative assessment of South African herbal medicine by means of HPLC fingerprinting. J Ethnopharmacol. 2005; 101:75-83

37. Willstatter R, Escher HH. Uber das Lutein des Huhnereidotters. Z Physiolog Chem. 1912;76:214-25.

38. Rudiger W. Biosynthesis of chlorophylls $a$ and $b$ and the chlorophyll circle. Photosynth Res. 2002;74:187-93.
39. Lim CK. High performance liquid chromatography and mass spectrometry of phorphyrins, chlorophylls and bilins. World Scientific Publishing Co., SGP, 2009; p. 177.

40. Gauthier A. Improved method to track chlorophyll degradation. Food Chem. 2001;49(3):1117-22

41. Milenkovic SM, Zvezdanovic JB, Andelkovic TD, Markovic DZ. The identification of chlorophyll and its derivatives in the pigment mixtures: HPLC-chromatography, visible and mass spectroscopy studies. Adv Tech. 2012;1(1):16-24.

42. Hsu CY, Yeh TH, Huang MY, Hu SP, Chao PY, Yang CM. Organ-specific distribution of chlorophyll related compounds from dietary spinach in rabbits. Indian J Biochem Biophys. 2014;51:388-95

\section{GRAPHICAL ABSTRACT}

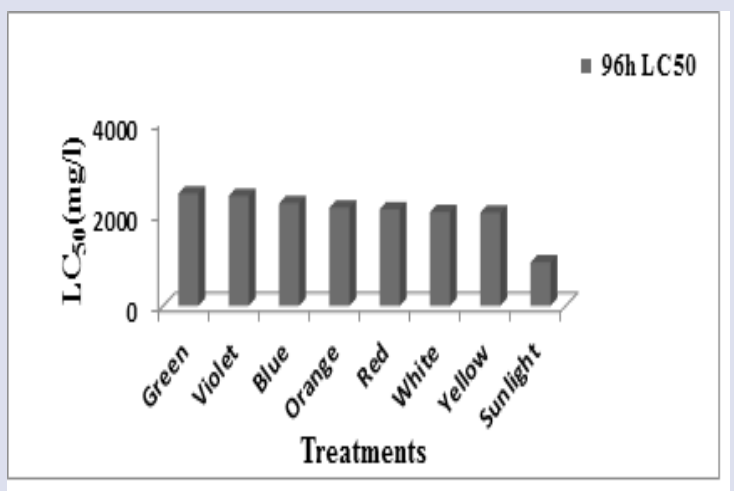

\section{SUMMARY}

- Fasciolosis is an imperative zoonotic helminthes disease throughout the world

- Chlorophyllin is a photodynamic product and more effective in sunlight.

- HPLC study reveals active component of extracted chlorophyllin is chlorophyllin a.

- Chlorophyllin is a very promising photodynamic substance and it has the potential to control the population of vector snails and ultimately fasciolosis in developing countries.

\section{ABOUT AUTHORS}

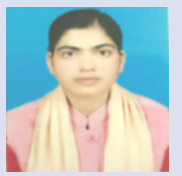

Divya Chaturvedi, Research Scholar of Malacology Laboratory, Department of Zoology, DDU Gorakhpur University, Gorakhpur, UP, India. She has completed her UG and PG from DDU Gorakhpur University, Gorakhpur and enrolled for her doctorate studied under the supervision of Dr. Vinay Kumar Singh. She has published 2 papers in an international journal and working on isolation, characterization and biological evaluation of natural products and pest control, vector-borne diseases from three years.

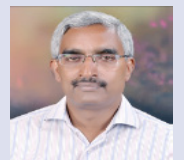

Professor D. K. Singh, Malacology Laboratory, Department of Zoology, DDU Gorakhpur University, Gorakhpur, UP, India has uni $\neg$ versity teaching and research experiences of more than 32 years. Current research interests are toxicology and molluscan physi-ᄀology. He has published 182 research papers, 14 review articles in 75 leading International Journals of repute with high impact factors. Dr. Singh publications have got 3019 citations all over world having $28 \mathrm{H}$-index and $87 \mathrm{i}-10$ index. Prof Singh has produced $27 \mathrm{Ph} . \mathrm{D}$. and successfully conducted 15 research projects.

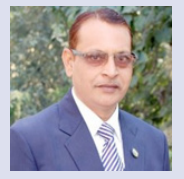

Dr. Vinay Kumar Singh, Assistant Professor stage-III, Department of Zoology, DDU Gorakhpur University, Gorakhpur, UP, India has university teaching and research experiences of more than 20 years. Current research interests are isolation, characterization and biological evaluation of natural products and pest control, vectorborne diseases. He has published 116 research papers, 11 review articles in 70 leading International Journals of repute with high impact factors. Dr. Singh has produced 11 Ph.D. students. Dr. Singh publications have got 808 citations all over world having $17 \mathrm{H}$-index and $23 \mathrm{i}-10$ index. Dr. Singh is serving as Editor-in-Chief of Research Journal of Parasitology, USA. Dr. Singh was nominated as member of University Court (JNU) by Hon'ble President of India.

Cite this article: Chaturvedi D, Singh DK and Singh VK. Photodynamic Toxicity of Chlorophyllin against Fasciola gigantica Carrier Snail Indoplanorbis exustus in Visible Spectral Band. Pharmacog J. 2017;9(6):729-36. 